EESTI NSV TEADUSTE AKADEEMIA TOIMETISED. 21. KOIDE KEEMIA * GEOLOOGIA. 1972, NR. 4

ИЗВЕСТИЯ АКАДЕМИИ НАУК ЭСТОНСКОИ ССР. ТОМ 21 ХИМИЯ * ГЕОЛОГИЯ. 1972, № 4

X. HECTOP

удК $551.733 .31(47+48+41)$

\title{
О ВОЗРАСТНОМ ДИАПАЗОНЕ СЛОЕВ С PENTAMERUS OBLONGUS И O ХАРАКTEPE ПОЗДНЕЛЛАНДОВЕРИИСКОЙ ТРАНСГРЕССИИ В СЕВЕРНОЙ ЕВРОПЕ
}

В Эстонии с верхним лландовери сопоставляется адавереский горизонт, четко подразделяющийся на две части: на известняки с Pentamerus oblongus, состоящие в свою очередь из нескольких пачек, и на мергели, аргиллиты и глины, рассматриваемые как велизеская пачка или свита (Rosenstein, 1939; Аалоэ, 1960; Кальо, 1962, 1970б; Юргенсон, 1966 и др.). Принимая точку зрения об одновозрастности пентамеровых известняков и велизеских мергелей, Д. Кальо (1962, 1970а) сопоставлял адавереский горизонт целиком с зонами от Spirograptus turriculatus до Monoclimacis crenulata граптолитовой шкалы, так как на юго-западе о. Сааремаа, в доломитовых аргиллитах скв. Охесааре, отнесенных к велизеской свите, встречаются граптолиты зон Spirograptusturriculatus (гл. 372,7-372,0 м), Monograptus crispus $(372-366$ м) и Monoclimacis griestoniensis (366353 м). Велизеские аргиллиты в этом разрезе покрыты отложениями, содержащими граптолиты зоны Cyrtograptus murchisoni (346-388 м).

Новейшие данные (Эйнасто и др., 1972) показывают, однако, что велизеские мергели залегают над пентамеровыми известняками, будучи целиком моложе их. Это позволяет по-другому интерпретировать также и корреляцию адавереских пентамеровых известняков с граптолитовой шкалой.

Небольшая мощность $(0,7 \boldsymbol{M})$ зоны Spirograptus turriculatus, установленная в разрезе скв. Охесааре, позволяет думать, что с этой зоной сопоставляется также какая-то часть из слоев с Pentamerus oblongus. С другой стороны, в скв. Охесааре слои с граптолитами зоны S. turriculatus залегают непосредственно над отложениями райккюлаского горизонта (средний лландовери) со значительным локальным перерывом (Мянниль, 1970; Әйнасто и др., 1972), возможно, охватывающим также и низы велизеских мергелей. Поэтому однозначное решение вопроса о корреляции нижней части адавереского горизонта с граптолитовой шкалой на основании одного разреза Охесааре невозможно.

В самих пентамеровых слоях адавереского горизонта находки граптолитов очень редки. А. М. Обут (1960) сообщает об обнаружении в этих слоях обломков рабдосом Climacograptus sp. indet, но более точно эти находки им не привязаны. Д. Кальо $(1970$ a, б) отмечает находку Barrandeograptus cf. gracilis Hemm. в обн. Пяэрду и Climacograptus sp. в низах пентамеровых слоев в скв. Ванаыуэ (гл. 19,9 м).

В скв. Икла, на юго-западе материковой части Әстонии, Д. Кальо (Кальо, Вингисаар, 1969) определил Climacograptus sp. $(312,4$ м) и 
Pseudoclimacograptus hughesi Nich. $(316,6$ м) в слоях, первоначально включенных в райккюлаский горизонт $(311,6-322,3$ м). На основе литологической корреляции и находок Pentamerus oblongus и акритархи Estiastra magna Р. Эйнасто и др. (1972) включили эту часть разреза в адавереский горизонт, сопоставляя ее с пентамеровыми слоями. Адавереский возраст данных находок климакограптид подтверждается еще на-

\section{UKЛA}

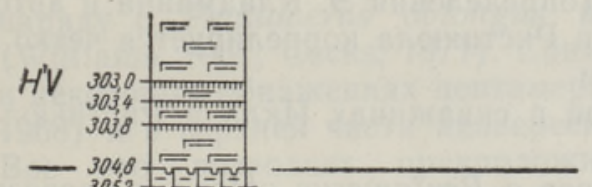
личием Placocoenites pellicula Klaamann (313,5 м; определение Э. Клааманна) и Beyrichia valguensis Sarv (310,5-321,2 ; определения Л. Сарва). Кроме того знаменательно, что в этой части разреза довольно часто

\section{РИСТИКЮЛА}

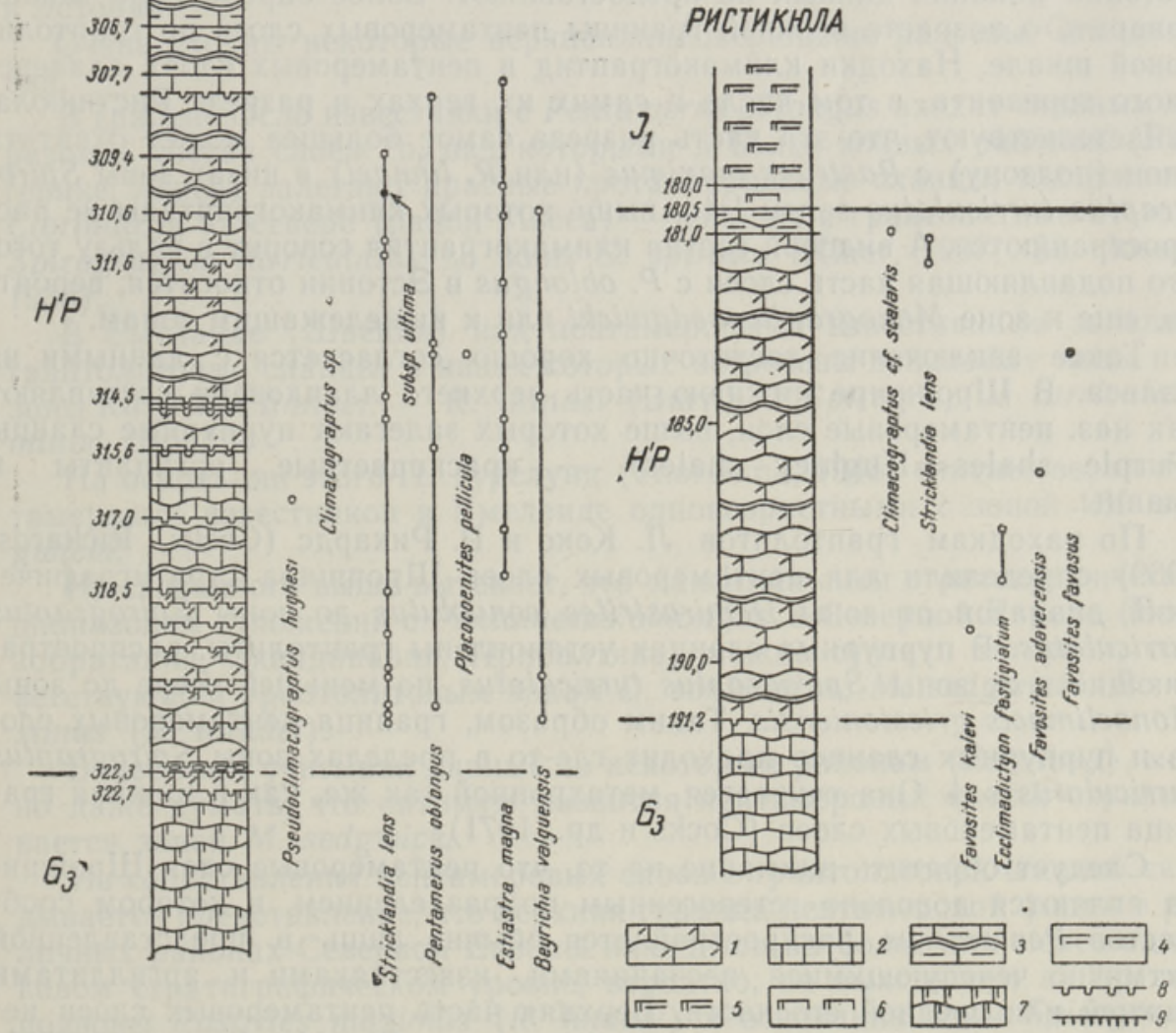

Распространение граптолитов и некоторых характерных для пентамеровых слоев видов в скважинах Икла и Ристикюла. Геологические колонки составлены по описаниям Р. Эйнасто и К. Каяка. $\mathrm{H}^{\prime} \mathrm{P}$ - пентамеровые слои, $\mathrm{H}^{\prime} \mathrm{V}$ - велизеские мергели. 1 - комковатый илисто-детритовый известняк; 2 - микро- и скрытокристаллический известняк; 3 - комковатый глинистый известняк $(\sim 50 \%)$ с прослоями глинистого мергеля $(\sim 50 \%) ; 4$ - глинистый мергель; 5 - глинистый домерит; 6 - известковый домерит; 7 - комковатый скрытокристаллический доломитистый известняк; 8 поверхность перерыва; 9 - прослойка метабентонита.

встречаются фрагменты Stricklandia lens (309,3-321,25 м). Однако до подвида среди последних удалось определить один экземпляр с гл. 310,15 м, который, по заключению М. Рубеля, принадлежит к подвиду 
Stricklandia lens ultima Williams, встречающемуся в стратотипическом регионе лландоверийского яруса в слоях $\mathrm{C}_{4-j}$ (Williams, 1951; Cocks, 1971).

В скв. Ристикюла, недалеко от Нкла, Д. Кальо определил Climacograptus cf. scalaris (His.) в верхах пачки комковатых глинистых известняков $(180,9$ м), содержащих характерные для адавереского горизонта виды табулят и строматопороидей: Favosites favosus (Goldf.) (183,5 м), F. adaverensis Sok. $(186,0$ м), F. kalevi Klmn. $(189,3$ м) и Ecclimadictyon fastigiatum Nich. (187,2 и 188,3 м) (определения Э. Клааманна и автора). Поэтому данная часть разреза в Ристикюла коррелируется четко с адаверескими пентамеровыми слоями.

Распространение названных видов в скважинах Икла и Ристикюла показано на рисунке.

О времени начала отложений слоев с Pentamerus oblongus разрезы Эстонии никаких данных не предоставляют. Более определенно можно говорить о возрасте верхней границы пентамеровых слоев по граптолитовой шкале. Находки климакограптид в пентамеровых слоях адавереского горизонта, в том числе в самих их верхах в разрезе Ристикюла, свидетельствуют, что эта часть разреза самое большее может охватить слои (подзону) с Rastrites maximus (или R. linnaei) в низах зоны Spirograptus turriculatus sensu lato, выше которых климакограптиды не распространяются. А видовой состав климакограптид говорит в пользу того, что подавляющая часть слоев с $P$. oblongus в Эстонии относится, вероятно, еще к зоне Monograptus sedgwicki или к нижележащим зонам.

Такое заключение достаточно хорошо согласуется с данными из Уэльса. В Шропшире нижнюю часть верхнего лландовери составляют так наз. пентамеровые слои, выше которых залегают пурпурные сланцы (Purple shales=Hughley shales) - красноцветные аргиллиты и сланцы.

По находкам граптолитов Л. Кокс и Р. Рикардс (Cocks, Rickards, 1969) определили для пентамеровых слоев Шропшира стратиграфический диапазон от зоны Demirastrites convolutus до зоны Spirograptus turriculatus. В пурпурных сланцах установлены граптолиты, распространяющиеся от зоны Spirograptus turriculatus по меньшей мере до зоны Monoclimacis griestoniensis. Таким образом, граница пентамеровых слоев и пурпурных сланцев проходит где-то в пределах зоны Spirograptus turriculatus s. 1. Она считается метахронной так же, как и нижняя гра. ница пентамеровых слоев (Cocks и др., 1971).

Следует обратить внимание на то, что пентамеровые слои Шропшира являются довольно гетерогенным подразделением, в котором сообщество Pentamerus распространяется обычно лишь в представленной ритмично чередующимися песчаниками, известняками и аргиллитами нижней или средней его части. Верхняя часть пентамеровых слоев нередко включает аргиллиты с сообществами Stricklandia и Clorinda (Ziegler и др., 1968) и тем уже близка к пурпурным сланцам. Граница между пентамеровыми слоями и пурпурными сланцами проводится главным образом по изменению окраски породы (Cocks, Rickards, 1969). Поэтому действительный стратиграфический диапазон пентамеровой фации в Шропшире явно меньше диапазона пентамеровых слоев как стратиграфического подразделения. В скважинах района Лонг Мюнд (Long Mynd), где Pentamerus oblongus встречается в разрезах одновременно с граптолитами, последние соответствуют лишь зонам Demirastrites convolutus и M. sedgwicki. Граптолиты, характерные для зоны S. turriculatus появляются в этих разрезах выше. Поэтому представляется вероятным, что отложения, содержащие сообщество Pentamerus oblongus в действи- 
тельности и в Шропшире тоже в подавляющей части древнее зоны $S$. turriculatus.

Кроме Шропшира, P. oblongus в Уэльсе встречается также в Лландовери, являясь характерным для слоев $\mathrm{C}_{1}$ и $\mathrm{C}_{4}$ (редко в $\mathrm{C}_{5}$ ). В слои $\mathrm{C}_{1}$ О. Джонс (Jones, 1925) включил сланцы Сефин с зональным видом M. sedgwicki. Слои $\mathrm{C}_{4}$ Л. Кокс (Cocks, 1971) по косвенным корреляциям сопоставляет с самыми верхами зоны M. sedgwicki и низами зоны S. turriculatus s. 1. Кроме того, в слоях $\mathrm{C}_{4}$ в окрестности Лландовери наряду с Pentamerus oblongus встречается Stricklandia lens ultima (Williams, 1951; Cocks, 1971). Совместно эти два вида встречаются еще в некоторых обнажениях пентамеровых слоев Шропшира (Ziegler и др., 1968) и в верхней части адавереских известняков Эстонии (см. выше). Bсе это позволяет предположить бо́льшую или меньшую синхронность верхов слоев с Pentamerus oblongus в Лландовери, Шропшире и Эстонии.

Очень сходны некоторые верхнелландоверийские разрезы Скандинавии.

В грабене Осло известняки с Pentamerus oblongus входят главным образом в состав слоев $7 \mathrm{~b}$, над которыми в более южных районах (Рингерике, Аскер) залегают красные кроталокриновые сланцы, содержащие Clorinda, а на севере (район Мьёса) - сланцы с граптолитами от зоны Spirograptus turriculatus до зоны S. spiralis (Kiaer, 1908; St. Joseph, 1938).

В Емтланде (Швеция) над пентамеровыми известняками залегают граптолитовые сланцы, в низах которых встречены зональные виды подзоны Rastrites linnaei $-R$. linnaei (Barr.) и Spirograptus turriculatus minor (Bouč.).

На основании этого П. Турслунд (Thorslund, 1948) считает верхи пентамеровых известняков в Емтланде одновозрастными с зоной $M$. sedgwicki.

Из сказанного выше вытекает, что максимальным стратиграфическим диапазоном отложений с Pentamerus oblongus в Северной Европе (Великобритания, Скандинавия, Прибалтика) можно считать интервал, соответствующий граптолитовым зонам D. convolutus, M. sedgwicki, R. maximus ( $R$. linnaei).

Более того, учитывая данные по некоторым районам (Емтланд), можно даже думать, что оптимум развития пентамеровых фаций ограничивается зоной $M$. sedgwicki.

Из сопоставления пентамеровых слоев с граптолитовой шкалой складывается представление, что верхняя граница пентамеровой фации в различных районах Северной Европы находится на более или менее одинаковом стратиграфическом уровне, вероятно, не выходящем за пределы подзоны Rastrites maximus (R. linnaei) в основании зоны Spirograptus turriculatus s. 1.

Это объясняется, очевидно, самим характером известной позднелландоверийской трансгрессии.

A. Циглер (Ziegler, 1965) высказал мнение, что в Уэльсе позднелландоверийская трансгрессия проходила в две стадии, объясняя стадийность двукратным эвстатическим углублением бассейна - в начале и в середине (в основании $\mathrm{C}_{5}$ ) позднелландоверийского века. Позже, однако, сложилось представление о более плавном прохождении этого процесca (Ziegler и др., 1968). Анализ приведенного в настоящей статье материала позволяет поддержать первоначальную точку зрения.

Мы видели, что в различных районах Северной Европы встречается определенный тип верхнелландоверийских разрезов, в которых относи- 
тельно более мелководные отложения пентамеровой фации (известняки или ритмично чередующиеся песчаники и аргиллиты) перекрываются значительно более глубоководными тонкозернистыми (часто красноцветными) отложениями с фауной сообщества Clorinda или же граптолитовой фацией.

Так как определяющим фактором распространения лландоверийских фаунистических сообществ считается глубина бассейна (Ziegier, 1965 и др.), то следует, что в рассмотренных нами районах (Уэльс, грабен Осло, Емтланд, Северная Прибалтика) углубление бассейна в середине позднего лландовери имело одинаковую амплитуду. Столь однотипные фациальные изменения, происходящие более или менее одновременно в отдаленных друг от друга районах с довольно различной геологической историей, тектоническим и седиментационным режимом, можно легче всего объяснить эвстатическим повышением уровня воды.

Эвстатическая природа резких фациальных изменений в середине позднего лландовери позволяет приписать им большое коррелятивное значение. Поэтому верхнюю границу пентамеровых слоев можно считать надежной стратиграфической границей. Ее значение повышается еще тем, что фациальным изменениям примерно на этом же уровне сопутствуют чисто биостратиграфические изменения в фациально однотипных сообществах. В граптолитовой фации это отражается в том, что подошва зоны S. turriculatus (то понимаемая в узком смысле, то включающая подзону R. maximus или $R$. linnaei) всегда считалась важной биостратиграфической границей. По ней проводилась, например, граница горизонтов Биркхилл и Гала (Тараннон) в Великобритании (Jones, 1921 и др.), и ярусов Желковице и Мотоль в Чехословакии (Bouček, 1960 и др.).

Заметные изменения происходили в течение позднего лландовери также в составах однотипных сообществ раковинной фауны. Во всех стратиграфически важных эволюционных рядах брахиопод в середине позднего лландовери отмечаются изменения. Они не происходили строго одновременно (см. Cocks, 1971), но в совокупности приводят к тому, что раковинная фауна низов и верхов верхнего лландовери различается очень четко.

В Балтийско-Скандинавском регионе возрастное различие фаун нижней и верхней половины позднего лландовери можно проследить при сравнении фаун фациально однотипных пентамеровых слоев Эстонии и Норвегии $(7 \mathrm{a}-\mathrm{b})$ и верхнего кораллового известняка $(7 \mathrm{c} \beta)$ Норвегии.

Верхний коралловый известняк содержит Pentameroides вместо Pentamerus и Costistricklandia lirata вместо Stricklandia lens. Э. Клааманн (1971) отмечает также четкое различие в ассоциациях табулят этих подразделений: пентамеровые слои адавереского горизонта Эстонии содержат ассоциацию Mesofavosites obliquus, некоторые элементы которой установлены также в слоях $7 \mathrm{a}$ и $7 \mathrm{~b}$ в Норвегии. Әта ассоциация полностью отличается от более молодой ассоциации Favosites stoermeri слоев 7с $\beta$ Норвегии.

Таким образом, можно заключить, что слои с Pentamerus oblongus, образующие в ряде районов Северной Европы нижнюю половину верхнего лландовери, являются не только фациальным, но, видимо, и хорошим хроностратиграфическим подразделением. Верхнюю границу этого подразделения, проходящего где-то на уровне подзоны Rastrites maximus можно считать ценным коррелятивным уровнем.

Автор признателен Д. Кальо, Э. Клааманну, М. Рубелю и Л. Сарву за использованные в статье палеонтологические определения, а также К. Каяку и Р. Эйнасто, по материалам которых составлены разрезы Ристикюла и Икла. 


\section{Л И Т Е Р А Т У Р А}

А алоэ А. О. 1960. Новое в стратиграфии силура Эстонии. Тр. Ин-та геол. АН ЭССР. V.

К а ль о Д. Л. 1962. О границе лландовери и венлока в Прибалтике. Тр. Ин-та геол. АН ЭССР, $\mathbf{x}$

К а льо Д. Л. 1970а. Граптолиты. В кн.: Силур Эстонии. Таллин.

Кал ьо Д. Л. 1970б. Адавереский горизонт. В кн.: Силур Эстонии. Таллин.

К альо Д., Вингиса ар П. 1969. О разрезе райккюлаского горизонта на южной окраине Эстонии. Изв. АН ЭССР, Хим. Геол., 18, № 3.

К л а а м а н Н. $Э 971$. Табуляты верхнего кораллового известняка Норвегии. Изв. АН ЭССР, Хим. Геол., 20, № 4.

О бу т А. М. 1960. Коррелящия некоторых частей разреза ордовикских и силурийских отложений Эстонской ССР по граптолитам. Тр. Ин-та геол. АН ЭССР, V.

Эйн а с то Р., Н естор Х., К ал а Э., К а як К. 1972. Сопоставление верхнелландоверийских разрезов в Западной Эстонии. Изв. АН ЭССР, Хим. Геол., 21, № 4. Юргенспн Э А 1065. Литология лландовепийских отложений Эстонии. Таллин.

B o 11 č e k B. 1960. Die Graptolithenfaunen des böhmischen Silurs und ihre stratigraphische Bedeutung. Prager Arbeitstagung über Stratigraphie Silurs und Devons, 1958. Praha.

Cocks L. R. M. 1971. Facies relationships in the European Lower Silurian. Mem. Bureau Recher. Geol. Miniers, 73.

Cocks L. R. M., R i c k a rd s R. B. 1969. Five boreholes in Shropshire and the relationships of shelly and graptolitic facies in the Lower Silurian. Quart. J. Geol. Soc. London, 124 , pt. 4.

Cocks L. R. M., Holl a nd C. H., Rickards R. B., St r a chan I. 1971. A correlation of Silurian rocks in the British Isles. J. Geol. Soc., 127, pt. 2.

J o n e s O. T. 1921. The Valentian Series. Quart. Journ. Geol. Soc. London, 77.

Jones O. T. 1925. The geology of the Llandovery district. Pt. I. The Southern area. Quart. J. Geol. Soc. London, 81, pt. 3.

Ki a e r .I 1908. Dis Obersilur im Kristianiagebiete. Kongl. Norsk Videnskapsselskapets Skr., 1, Math.-Naturwiss. Kl., 2.

Rosenstein E. 1939. Adavere lademest (silur) Lääne-Eestis. Eesti Loodus, 7, nr. 4/5. St. Jos e p h J. K. S. 1938. The Pentameracea of the Oslo region. Norsk Geol. Tidsskr., 17, H. 4.

Thorslund P. 1948. De siluriska lagren ovan Pentamerus-kalkstenen i Jämtland. Sverige Geol. Unters., Ser. C, No. 494.

Willi a m s A. 1951. Llandovery brachiopods from Wales with special reference to the Llandovery district. Quart. Journ. Gəol. Soc. London. 107, pt. 1.

$\mathrm{Z}$ i e g l e r A. M. 1965. Silurian marine communities and their environmental significance. Nature, 207, No. 4994.

$\mathrm{Z}$ i e g l e r A. M., C ocks L. R. M., M c K e r r ow W. S. 1968. The Llandovery transgression of the Welsh Borderland. Palaeontology, 11, pt. 5.
Институт геологии
Академии наук Эстонской ССР
Поступила в редакцию
5/IV 1972

\section{H. NESTOR}

\section{PENT AMERUS OBLONGUS-KIHTIDE STRATIGRAAFILISEST DIAPASOONIST JA HILISLÄNDOUVERI TRANSGRESSIOONI OLEMUSEST PŌJA EUROOPAS}

Otseste graptoliidileidude pōhjal võib Pentamerus oblongus'e kooslust sisaldavate kihtide maksimaalseks stratigraafiliseks diapasooniks pidada intervalli, mis vastab Demirastrites convolutus'e, Monograptus sedgwicki ja Rastrites maximus'e $(R$. linnaei) tsoonile graptoliidiskaalas. Pentąmerus-faatsiese ülemine piir on tõenäoliselt üsna sünkroonne ja kulgeb kuskil $R$. maximus'e tsooni tasemel. Eestis, Oslo alangus, Jämtlandis ja Wales'is lasuvad pentaameruskihtidel tunduvalt sügavamaveelise geneesiga setted, mis sisaldavad kas Clorinda-kooslust vōi graptoliite. Ohetüübilised fatsıaaisea muutused üksteisest kaugel asuvais läbilöigetes annavad tunnistust ülemländouveri transgressiooni eustaatilisest iseloomust. 


\section{ON THE STRATIGRAPHIC RANGE OF THE BEDS WITH PENTAMERUS OBLONGUS AND ON THE NATURE OF THE LATE LLANDOVERIAN TRANSGRESSION IN NORTH EUROPE}

In Estonia the Pentamerus oblongus Beds (H'P) of the Adavere Stage ( $=$ the regional equivalent of the Upper Llandovery) were considered earlier to be contemporaneous with the Velise Marls (H'V) containing graptolites of Spirograptus turriculatus, Monograptus crispus and Monoclimacis griestoniensis Zones. As recently established, the Pentamerus Beds underlie the Velise Beds synchronously (Эйнасто et al., 1972) and contain climacograptids, showing that the Pentamerus Beds in Estonia are not younger than the Rastrites maximus (R. linnaei) Band in the lowermost part of the S. turriculatus Zone sensu lato. The major part of the Pentamerus Beds is probably of pre-turriculatus Zone age (new records of graptolites from the Pentamerus Beds of Estonia are shown in Fig. 1).

In Wales the beds with the Pentamerus oblongus community (Pentamerus Beds in Shropshire, $\mathrm{C}_{1}$ and $\mathrm{C}_{4}$ in Llandovery) carry graptolites indicating Demirastrites convolutus, M. sedgwicki and S. turriculatus Zones (Cocks, Rickards, 1969). In Shropshire the S. turriculatus Zone is also proved for the lower part of the overlying Purple Shales. The actual range of the Pentamerus community does not coincide with the range of Pentamerus Beds as a stratigraphic unit, but is restricted to its lower or middle portion, only. Therefore in Shropshire the top of the beds containing the Pentamerus community may be correlated as maximum with the lower part of the S. turriculatus Zone s.1., most probably with the $R$. muximus Band only.

In Oslo region (Norway) the " $7 \mathrm{~b}$ " Beds with $P$. oblongus underlie the " $7 \mathrm{c}$ " mudstones and shales that carry graptolites of the $S$. turriculatus up to the $S$. spiralis Zone in Mjösen district. In Jamtland (Sweden) zonal species of $R$. linnaei Zone $(=R$. maximus Band) were reported from the black shales just above the top of the Pentamerus Limestones (Thorslund, 1938).

Thus in North Europe the maximum range of the $P$. oblongus Beds probably coincides with the $D$. convolutus, $M$. sedgwicki and $R$. maximus ( $R$. linnaei) Zones in the graptolitic succession.

In all the above-mentioned regions merely shallow-water Pentamerus-facies (shelly limestones or intercalating mudstones, limestones and sandstones) are overlain by much more deep-water lutite sediments (mudstones with the Clorinda community or graptolitic shales). Such completely analogical facial changes, occurring in several remote stratigraphic sections of North Europe on the level of the R. maximus Zone, could be most easily explained by the eustatic nature of the Late Llandoverian transgression. The same stratigraphic level also roughly coincides with purely biostratigraphic changes in the faunal communities of the same facial type. Therefore the upper boundary of the Upper Llandoverian Pentamerus Beds may be considered as a remarkable stratigraphic boundary. 